University of Nebraska - Lincoln

DigitalCommons@University of Nebraska - Lincoln

USDA Wildlife Services - Staff Publications

U.S. Department of Agriculture: Animal and Plant Health Inspection Service

2018

Costs and effectiveness of damage management of an overabundant species (Sus scrofa) using aerial gunning

\author{
Amy J. Davis \\ USDA National Wildlife Research Center, Amy.J.Davis@usda.gov \\ Bruce Leland \\ USDA APHIS Wildlife Services \\ Michael Bodenchuk \\ USDA APHIS Wildlife Services \\ Kurt C. VerCauteren \\ USDA National Wildlife Research Center, kurt.c.vercauteren@usda.gov \\ Kim M. Pepin \\ USDA National Wildlife Research Center
}

Follow this and additional works at: https://digitalcommons.unl.edu/icwdm_usdanwrc

Part of the Life Sciences Commons

Davis, Amy J.; Leland, Bruce; Bodenchuk, Michael; VerCauteren, Kurt C.; and Pepin, Kim M., "Costs and effectiveness of damage management of an overabundant species (Sus scrofa) using aerial gunning" (2018). USDA Wildlife Services - Staff Publications. 2223.

https://digitalcommons.unl.edu/icwdm_usdanwrc/2223

This Article is brought to you for free and open access by the U.S. Department of Agriculture: Animal and Plant Health Inspection Service at DigitalCommons@University of Nebraska - Lincoln. It has been accepted for inclusion in USDA Wildlife Services - Staff Publications by an authorized administrator of DigitalCommons@University of Nebraska - Lincoln. 


\title{
Costs and effectiveness of damage management of an overabundant species (Sus scrofa) using aerial gunning
}

\author{
Amy J. Davis (D) A,C, Bruce Leland ${ }^{\mathrm{B}}$, Michael Bodenchuk ${ }^{\mathrm{B}}$, Kurt C. VerCauteren ${ }^{\mathrm{A}}$ \\ and Kim M. Pepin ${ }^{\mathrm{A}}$ \\ ANational Wildlife Research Center, Wildlife Services, Animal Plant Health Inspection Service, \\ United States Department of Agriculture, 4101 Laporte Avenue, Fort Collins, CO 80521, USA. \\ ${ }^{B}$ Wildlife Services, Animal Plant Health Inspection Service, United States Department of Agriculture, \\ San Antonio, TX 78269, USA. \\ ${ }^{\mathrm{C} C o r r e s p o n d i n g ~ a u t h o r . ~ E m a i l: ~ a m y . j . d a v i s @ a p h i s . u s d a . g o v ~}$
}

\begin{abstract}
Context. Management of overabundant or invasive species is a constant challenge because resources for management are always limited and relationships between management costs, population density and damage costs are complex and difficult to predict. Metrics of management success are often based on simple measures, such as counts, which may not be indicative of impacts on damage reduction or cost-effectiveness under different management plans.

Aims. The aims of this study were to evaluate the effectiveness of aerial gunning for the management of wild pigs (Sus scrofa), and to evaluate how cost-effectiveness would vary under different relationships between levels of damage and densities of wild pigs.

Methods. Repeated reduction events were conducted by aerial gunning on three consecutive days at three study sites. Using a removal model, the proportion of the population removed by each flight was estimated and population modelling was used to show the time it would take for a population to recover. Three possible damage-density relationships were then used to show the level of damage reduction (metric of success) from different management intensities and levels of population recovery, and these relationships were expressed in terms of total costs (including both damage and management costs).

Key results. Populations were typically reduced by $\sim 31 \%$ for the first flight, $\sim 56 \%$ after two flights and $\sim 67 \%$ after three flights. When the damage relationship suggests high damage even at low densities, the impact of one, two or three flights would represent a reduction in damage of $2 \%, 19 \%$ and $60 \%$ respectively after 1 year. Different damage relationships may show considerable damage reduction after only one flight. Removal rates varied by habitat $(0.05$ per hour in open habitats compared with 0.03 in shrubby habitats) and gunning team ( 0.03 versus 0.05$)$.

Conclusions. Monitoring the efficacy of management provides critical guidance and justification for control activities. The efficacy of different management strategies is dependent on the damage-density relationship and needs further study for effective evaluation of damage reduction efforts.

Implications. It is critically important to concurrently monitor density and damage impacts to justify resource needs and facilitate planning to achieve a desired damage reduction goal.
\end{abstract}

Additional keywords: cost-benefit analyses, damage reduction, feral swine, invasive species, monitoring, population reduction, wildlife management.

Received 21 November 2017, accepted 5 October 2018, published online 18 December 2018

\section{Introduction}

An important element in any wildlife management program, including for invasive species, is monitoring the state of the system (Hauser et al. 2006; Lyons et al. 2008; Fackler and Haight 2014) to allow for evaluation and refinement of management actions. To establish meaningful metrics of management success, it is important to define the management objective clearly. For many game species, the objective is to maintain a viable population while keeping the population under a threshold that minimises human-wildlife conflicts and damage (Diefenbach et al. 1997; Fagerstone and Clay 1997; VerCauteren et al. 2011). In these situations, changes in abundance provide an evaluation of the efficacy of management (Diefenbach et al. 1997; Rupp et al. 2000). In contrast, for invasive species or overabundant populations, where the objective is to reduce damage (Conover 2001; Campbell and Long 2009; Bleier et al. 2012), changes in damage levels are the most important metric of management 
success (Hone 1996). When the underlying objective is costeffectiveness, then the impact on the population, the damage costs and costs for removal actions need to be combined to make the best decision.

A common method for monitoring managed wildlife populations is using count data, which can be harvest counts (Rupp et al. 2000; Linnell et al. 2010), management take counts (Slade and Blair 2000) or index survey counts (DeMaso et al. 1992; Bengsen et al. 2011). Many advancements have been made in how these types of count data are analysed, including (but not limited to) population reconstruction for harvest data (Gove et al. 2002), removal models for take data (Zippin 1958) and distance sampling for count surveys (Buckland et al. 2001). When populations are being actively controlled, take data from management actions are routinely collected. Removal models provide estimates of initial abundance, proportion removed, remaining abundance and removal rate (Farnsworth et al. 2002; St. Clair et al. 2012; Davis et al. 2016). However, removal models require multiple removal events within a period of demographic closure, which is often not how management activities are conducted. In these cases, the metrics used to measure short-term success of management may not be indicative of long-term success (Shrnhur et al. 1997), making it challenging to determine the probability of long-term success. When counts of take are the measure of success for short-term management, managers are incentivised to focus efforts in high-density areas, and shift resources when body counts decline, because it requires less effort to remove large numbers of individuals when population density is high. Therefore, conducting multiple removal events may not be thought of as cost-effective when only management costs are considered because management costs increase as population densities decline (Baxter et al. 2008). Thus, counts of individuals removed could provide some measure of management success when population densities are high, but provide less information when population densities are low and, on their own, do not allow for assessment of whether a particular damage reduction objective was met.

Population growth rates and models can be used to project population size in time and, thus evaluate the time it takes for a population to rebound after a reduction event - the long-term impacts of management. If population management is sporadic or continuous, the rebound timing gives a sense of the level of management needed to make a lasting impact on the population. An understanding of long-term population dynamics allows for prediction of the effects of different reduction efforts on long-term damage reduction. In addition to potential non-linear impacts of population reduction on long-term management success, the impact of different population densities may relate non-linearly to wild pig damage (Hone 2002). Damage is a complex and variable metric to estimate, but is important to quantify for ensuring that economic resources are being allocated efficiently.

Wild pigs (Sus scrofa) are a global pest species and an invasive species in the Americas and Australia (BarriosGarcia and Ballari 2012; Bengsen et al. 2014; Bevins et al. 2014). Wild pig populations have grown and their range has expanded over the last three decades in the United States of America (Bevins et al. 2014; Snow et al. 2017). Increasingly, resources have been applied to slow the spread of wild pigs and reduce the damage to crops, infrastructure and other species (Seward et al. 2004; Campbell and Long 2009; Bevins et al. 2014). Many methods are currently in use to reduce wild pig population sizes, including aerial gunning (Campbell et al. 2010; Parkes et al. 2010), trapping and snaring (Choquenot et al. 1993; Caley 1994; Williams et al. 2011), hunting (NaughtonTreves 1998; Waithman et al. 1999), and new methods, such as toxicants and fertility treatments, are being developed (Cowled et al. 2008; Massei et al. 2008; Snow et al. 2017). Aerial gunning is known to be an efficient method for removing wild pigs (Choquenot et al. 1999; Parkes et al. 2010; Davis et al. 2017). While it is well documented that costs of removing pigs by aerial gunning increase dramatically as population decreases (Choquenot et al. 1999), its cost-effectiveness in terms of damage reduction is unknown.

The relationship between damage and density is not well understood, particularly for wild pigs. Wild pigs cause an enormous amount of damage in the United States of America, with one estimate around USD1.5 billion in damages per year (Pimentel 2007). There is considerable effort being employed to reduce the damage caused by this invasive species. Understanding the relationship between wild pig densities and the amount of damage they inflict is critical to reducing damage efficiently and cost-effectively because it helps inform how many pigs need to be removed to reach a desired damage level.

To improve the ability to predict cost-effectiveness of wild pig management programs, we analysed data from aerial gunning of wild pigs at three sites in Texas, USA. We examined effects of three damage-density relationships on potential costs and effectiveness of the wild pig damage management work to give examples of how these factors will influence the decision matrix of managers. Our specific objectives were to: (1) estimate the effectiveness and costs of repeating aerial gunning over the same space - both in the short and long-term; (2) quantify factors that affect effectiveness of aerial gunning; and (3) examine the effects of different wild pig density-damage relationships on effectiveness and costs.

\section{Methods}

We conducted wild pig reductions in three habitats in Texas. Site 1 was an open semiarid desert habitat along the Pecos River in Culberson, Reeves, Loving and Ward counties. Most of the $850-\mathrm{km}^{2}$ site consisted of shrub land and barren land, with less than $2 \%$ of either woody wetlands or cultivated crops immediately around the Pecos River (Homer et al. 2015). Site 1 was in the trans-Pecos portion of the state and removal work was conducted in this area to prevent the spread of wild pigs north and west and prevent future damage, rather than to reduce current damage. Thus, damage reduction was not a direct objective at this site. Site 2 was a $105-\mathrm{km}^{2}$ area in dense cedar and live-oak habitat in Burnet County. Approximately 65\% of Site 2 was forested, $\sim 32 \%$ was shrub and grassland, with $<3 \%$ developed open space and open water (Homer et al. 2015). Site 3 was a 122-km² area in a coastal plain habitat in Matagorda County. This site had woody wetlands as a dominant feature (49\%), 20\% was pastureland, $15 \%$ was shrub and grassland and $\sim 7 \%$ dense hardwood (Homer et al. 2015). In Sites 2 and 3, damage reduction was the main 
objective. All study areas are on private land and were conducted at the request of the landowner.

We used aerial gunning from helicopters to remove wild pigs from each study area. Aerial gunning was conducted by the United States Department of Agriculture (USDA) Animal and Plant Health Inspection Service (APHIS) Wildlife Services (WS), which provides wildlife control assistance to land owners based on the authority of the Animal Damage Control Act of 1931 (7 USCA $\S 8351-8354$ ) and in compliance with the National Environmental Policy Act (42 U.S.C. $\S$ 4321). The objective was to remove (kill) all pigs encountered; the search strategy used was based on the expert opinion of the pilot and gunner team and included searching the entire study area. Flights over Site 1 were conducted in April 2016, flights over Site 2 were conducted in June 2016, and flights over Site 3 were conducted in July 2016. Three flights per site were conducted on subsequent days. We had two pilot and gunner teams (A and B). Team A had 10-12 years of experience conducting aerial gunning, and Team B had 5-7 years of experience conducting aerial gunning. In Site 1, Team A flew on the first day, then Team $\mathrm{B}$ on the second day, and then Team A again on the third day. This was the same for Site 3, but the order was switched for Site 2 . Flights were conducted with minimal winds (considerably less than the visual flight rules requirements of $26 \mathrm{kn}$ ) and no precipitation. Total flight times were generally between 6 and $8 \mathrm{~h}$ per day, excluding time on the ground for refueling. Twelvegauge shotguns were used with double-aught buckshot. Care was taken to ensure all shot animals were killed (animal was seen to collapse and was often double tapped - two shots fired in rapid succession at the same target, and shot animals were flown back over to verify they were down before moving on). The number of animals removed and the hours in the helicopter were recorded for each flight.

We estimated abundance from the aerial gunning data using a removal model that simultaneously estimates abundance and removal rates from counts of removed individuals (Farnsworth et al. 2002; Royle and Dorazio 2006). We implemented the removal model in a hierarchical Bayesian framework that accounted for variation in removal effort (Davis et al. 2016). Removal models require multiple reduction events within a time period in which there is demographic closure (no births, deaths, immigration, and emigration). Removal estimators are advantageous for monitoring abundance of invasive species because they directly use data from control events (Zippin 1958; Farnsworth et al. 2002; Chee and Wintle 2010) for estimation of abundance pre-control. From the estimates of abundance pre-control and numbers of individuals removed, the proportion by which the population is reduced due to control can be derived. We also incorporated covariates on removal rate; specifically, personnel and habitat (see Supplementary Material 1 for model details). We compared the removal rates for the two pilot and gunner teams, and examined the relationship with the proportion of forest cover (as determined from Homer et al. 2015). We estimated the population remaining after each flight by subtracting the number removed by flight from the estimate of initial abundance. We then derived the proportion of the population removed by each flight by dividing the number removed by each flight by the estimated population size pre-flight.
To examine the long-term impact that reductions had on populations, we used a standard logistic population growth model (Sibly and Hone 2002; Otto and Day 2007) to predict abundance at 1, 3 and 5 years following a reduction event. We used estimates of population growth rate and density dependence from previous studies to provide the boundaries for our modelling (Caley 1993; Bieber and Ruf 2005; Timmons et al. 2012; Mellish et al. 2014). Previous studies on wild pig populations have estimated growth rates ranging from 0.85 to 1.63 (Bieber and Ruf 2005), with the majority of growth-rate estimates between 1.15 and 1.35 with a mean of 1.24 (Bieber and Ruf 2005; Timmons et al. 2012; Mellish et al. 2014; Moretti 2014). We examined a range of growth rates $(\lambda)$ from 1 to 2 to provide a broader picture of population growth rates that may be exhibited.

Management programs for wild pigs are often aimed at reducing damage caused by wild pigs. Damage costs can range from quantifiable assessments of lost crops, infrastructure repairs and livestock feed loss, to more abstract costs associated with disease risks, landscape rooting and predation or competition of native imperilled or game species. Damage costs are a combination of all of these factors; however, there are areas with little or no current damage costs but with the potential for great damage if wild pigs are able to establish a population in an area. Therefore, damage reduction can be in current costs as well as the prevention of future costs.

The relationship between wild pig population densities and damage incurred by wild pigs is not well known, but studies have suggested that the damage-density relationship for species in general is not necessarily linear (Hone 1995; West and Parkhurst 2002). To demonstrate the importance of knowing the shape of the damage-density relationship for wild pigs, we show the impacts of damage under three potential relationships (Fig. 1): linear (damage and density are linearly related); saturating (even

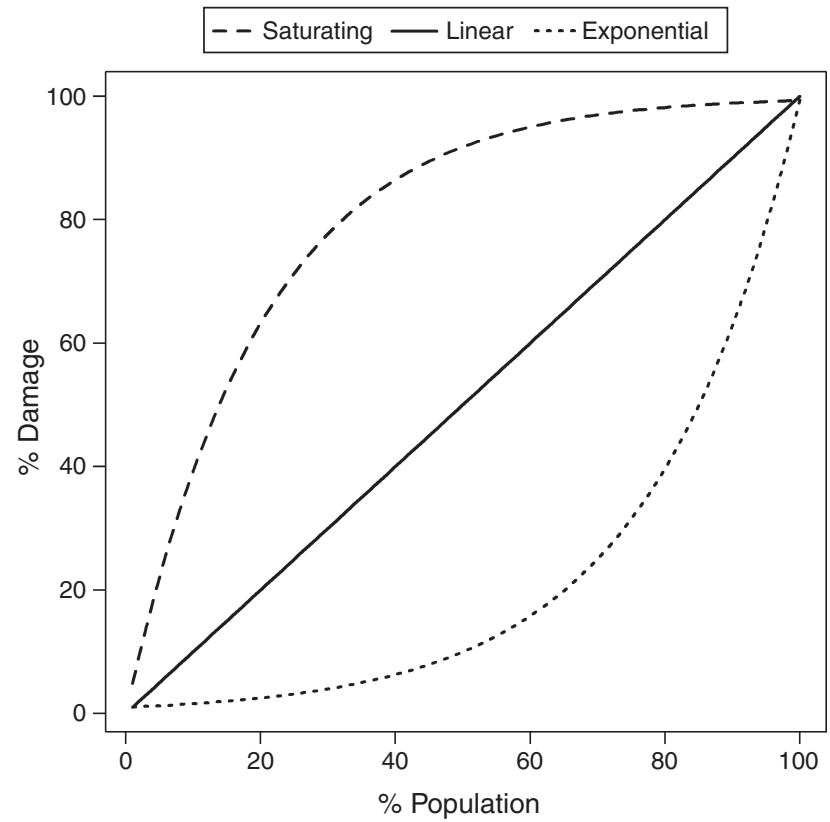

Fig. 1. Theoretical relationships between the percentage of a population remaining and the percentage of total damage remaining. 
at low levels of density the damage is high); and exponential (only at high levels of density is the damage high). We compared percentage damage reduction after 1,3 and 5 years by varying levels of percentage population reduction (ranging from $0 \%$ to $100 \%$ reduction) and growth rate $(\lambda=1-2)$ under the three damage relationships.

The damage was not explicitly estimated directly at the sites in our study. Therefore, we examined hypothetical damage costs to examine the cost-benefits of different levels of management effort. Damage can be to crops, pastureland or infrastructure. In our study areas, the damage was on pastureland. The costs may depend on the type of damage, so we examined a range of values based on average values for different land types per acre and different numbers of acres. The range is flexible (\$0-\$150 000) to account for different types of damage and different sizes of properties. We used the range of damage costs to compare the relative damage costs and management costs of wild pigs across a range of percentage population reductions ( $0 \%$ to $100 \%)$. Estimated costs of helicopter removal work was based on the hourly rate charged for the reduction work we conducted (USD625 per hour).

\section{Results}

We removed 324, 147 and 362 wild pigs from Sites 1, 2 and 3, respectively, across all flights conducted. The total number removed by flight and the time spent in the helicopter are shown by site and flight in Table 1 . We estimated initial abundance at Sites 1-3 to be 413 (95\% credible intervals CI: 297 - 481), 268 (95\% CI: 200-318), and 545 (95\% CI: 387-646), respectively (Fig. 2). The average proportion of the population removed after the first flight was $31 \%($ s.e. $=6 \%)$, cumulatively after the second flight was $56 \%$ (s.e. $=15 \%$ ), and cumulatively after the third flight was $67 \%$ (s.e. $=12 \%$ ).

Removal rates differed based on the pilot and gunner team (Fig. $3 A$ ). In our example, Team A had a lower hourly removal rate $(0.03$ 95\% CI: $0.02,0.04)$ than Team B $(0.0595 \%$ CI: 0.04 , 0.06 , Fig. $3 A)$. We found removal rate decreased as percentage cover increased $(\beta=-0.5595 \% \mathrm{CI}:-0.79,-0.27$, Fig. $3 B)$.

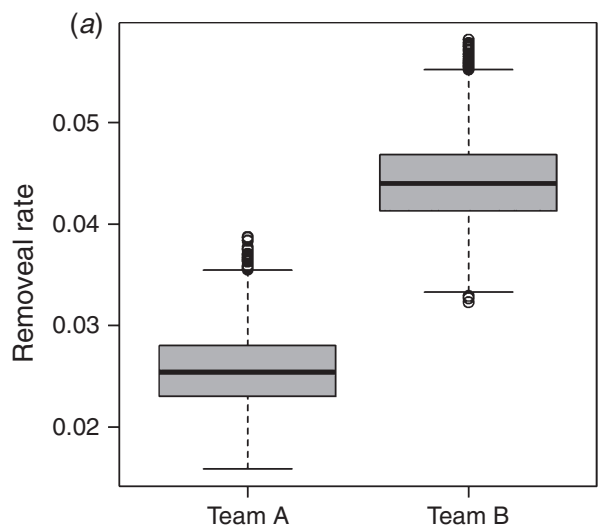

Growth rates impacted the linear damage relationship more substantially than either the saturating or the exponential relationships (Fig. 4). At slower growth rates, there was still

Table 1. Raw data from pilot study removing wild pigs from three study sites in Texas from aerial gunning work by site

\begin{tabular}{llccr}
\hline Habitat & $\begin{array}{l}\text { Pilot and } \\
\text { gunner team }\end{array}$ & Flight & $\begin{array}{c}\text { No. wild } \\
\text { pigs removed }\end{array}$ & Hours \\
\hline Site 1 & Team A & 1 & 157 & 8 \\
& Team B & 2 & 140 & 8 \\
& Team A & 3 & 27 & 6.7 \\
Site 2 & Team B & 1 & 71 & 7.5 \\
& Team A & 2 & 43 & 7.5 \\
\multirow{3}{*}{ Site 3 } & Team B & 3 & 33 & 8 \\
& Team A & 1 & 161 & 7 \\
& Team B & 2 & 125 & 6.9 \\
& Team A & 3 & 76 & 5.9 \\
\hline
\end{tabular}

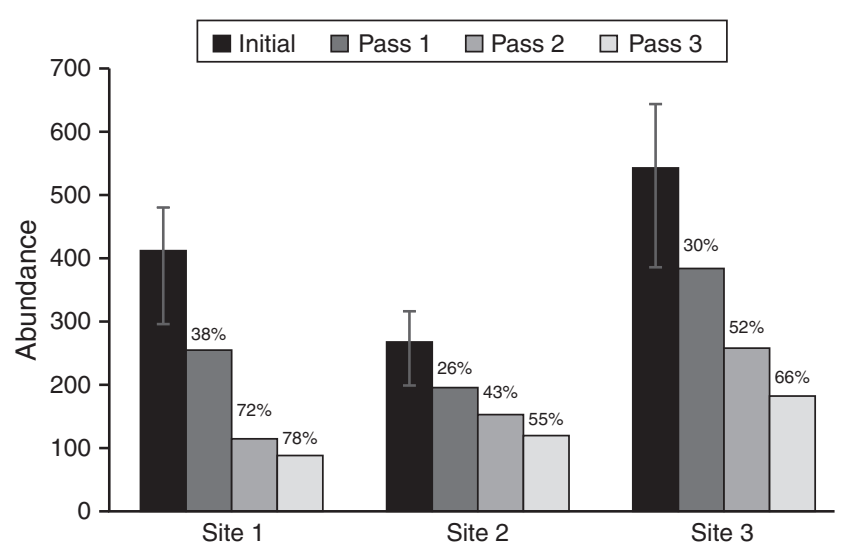

Fig. 2. Abundance estimate (with $95 \%$ confidence intervals for the initial abundance) by site for the initial population size and the subsequent size after each flight. The proportion of the population removed is shown in text by flight above the abundance estimate.

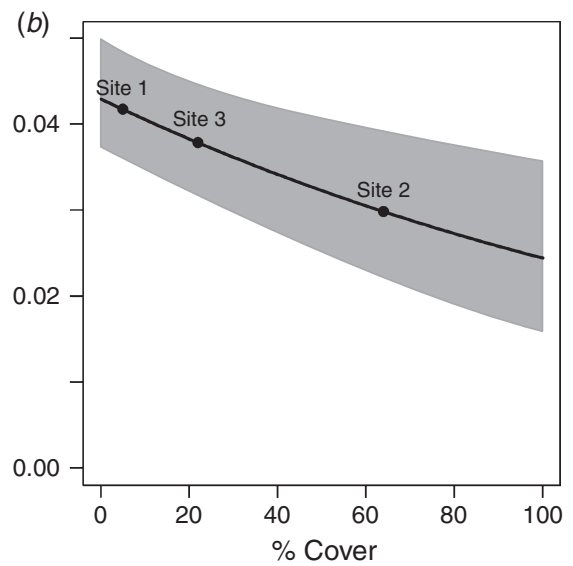

Fig. 3. (A) Boxplot of the posterior distributions of hourly removal rates by pilot and gunner team. The grey boxes represent the interquartile range, the dotted lines show the $95 \%$ credible intervals and the circles represent the total range of the posterior distributions. $(B)$ Relationship of hourly removal rate and the percentage cover; the shaded region represent the $95 \%$ credible intervals. Points shown represent the percentage forest cover by site. 


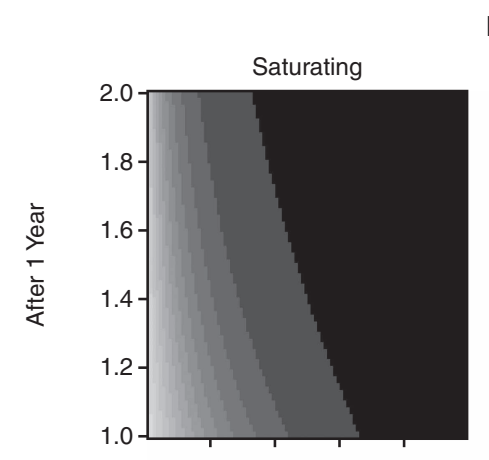

Damage-density relationships
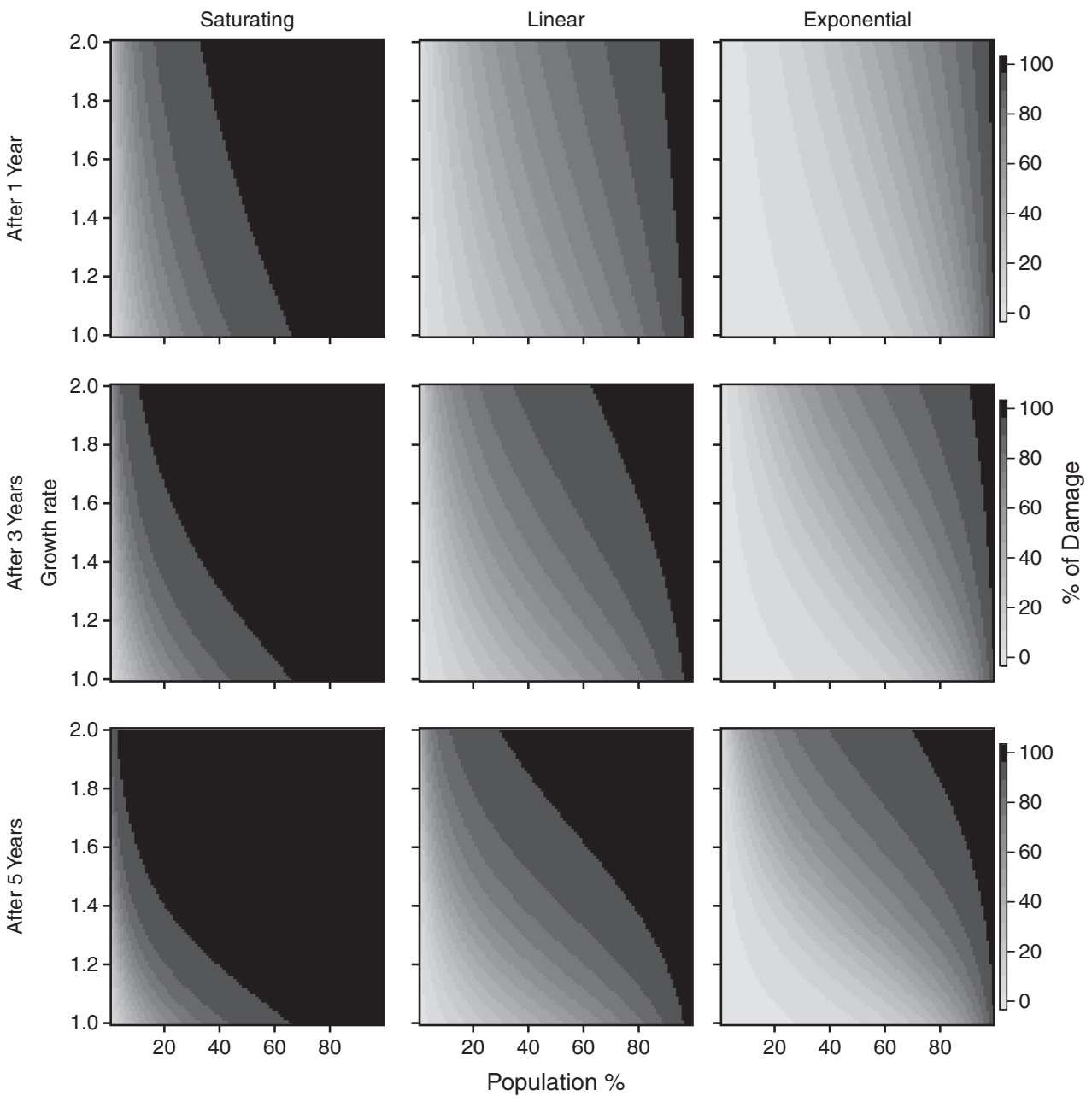

Fig. 4. Percentage of total damage (as calculated without any wild pig reduction) by the percentage of the initial wild pig population (e.g. $20 \%$ population corresponds to an $80 \%$ reduction in wild pigs) and potential values of wild pig growth rates. The percentage of total damage is shown cumulatively for three time frames $(1,3$ and 5 years post reduction event, shown in rows), and for three different potential damage-density relationship (saturating, linear and exponential, shown in columns).

damage reduction for all density-damage relationships after 5 years when $40 \%$ or less of the population was removed (Fig. 4).

The hours of aerial gunning required grew exponentially as the proportion of the population removed increased (Fig. $5 \mathrm{~A}$ ). When the hourly removal rate was greater than 0.1 , the effort required to remove up to $90 \%$ of a population was reasonable $(<20 \mathrm{~h}$ of flight time, Fig. $5 B)$. If the hourly removal rate was 0.04 (as was the average in our study), the effort needed to remove more than $90 \%$ of the population was more than $45 \mathrm{~h}$ (Fig. $5 \mathrm{~A}$ ).

The relationship between the reduction in damage costs and removal costs is an important factor in evaluating the cost-effectiveness of management actions. For a saturating damage-density relationship, the population needed to be reduced substantially ( $80 \%$ or more) for the damage reduction costs to outweigh the removal costs (Fig. 6A). The total costs for the linear relationship and the exponential relationship only showed high overall costs when the initial damage costs were high and the population reduction was low (Fig. 6B, C).
We compared the overall costs with the initial damage costs to determine if the resulting removal effort resulted in an economic gain or loss over doing nothing. For the saturating relationship, we found that damage costs must be greater than USD50 000 and more than $60 \%$ of the population must be removed to see an economic gain over baseline damage costs (Fig. 6D). If the damage relationships were either linear or exponential, there was generally a cost saving to removing at least some portion of the population for almost all levels of damage (Fig. 6E, F).

\section{Discussion}

For other ungulate species, the damage-density relationship has been estimated to be high even at low densities - similar to the saturating relationship we presented (Gill 1992; Hone 2002; West and Parkhurst 2002). Under the saturating relationship, we found that the proportion of the population that needs to be removed in order to have a substantial effect on damage can be 


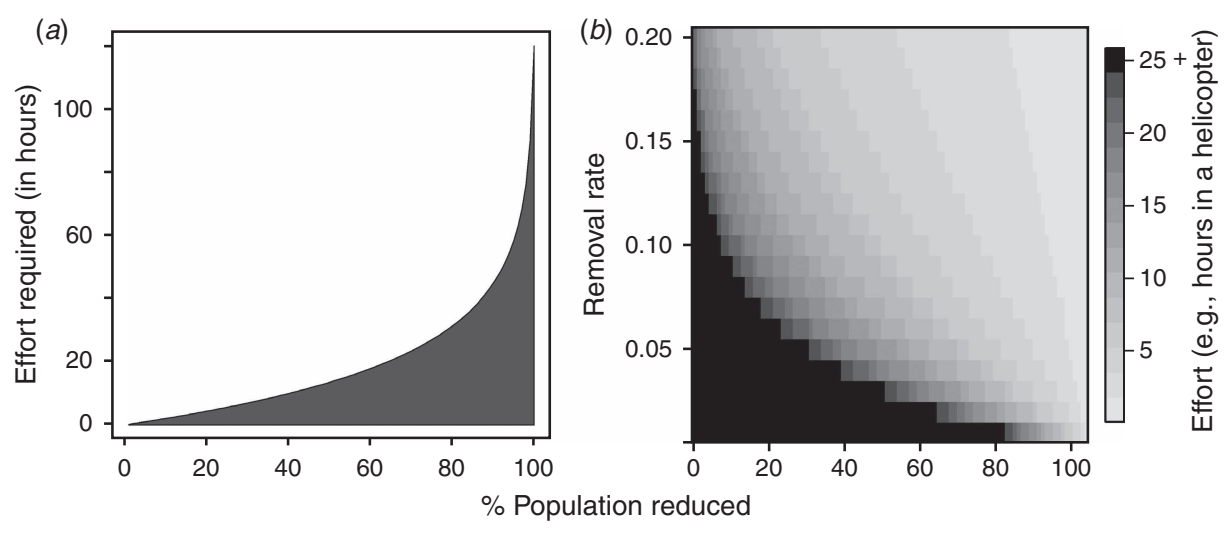

Fig. 5. (A) The effort required is plotted against the percentage of the population removed based on a removal rate for one hour of effort of 0.04 , which was estimated from our data. (B) Reduction effort (hours in a helicopter) necessary to remove varying proportions of the population ( $x$-axis) by the removal rate given one hour of effort (y-axis).
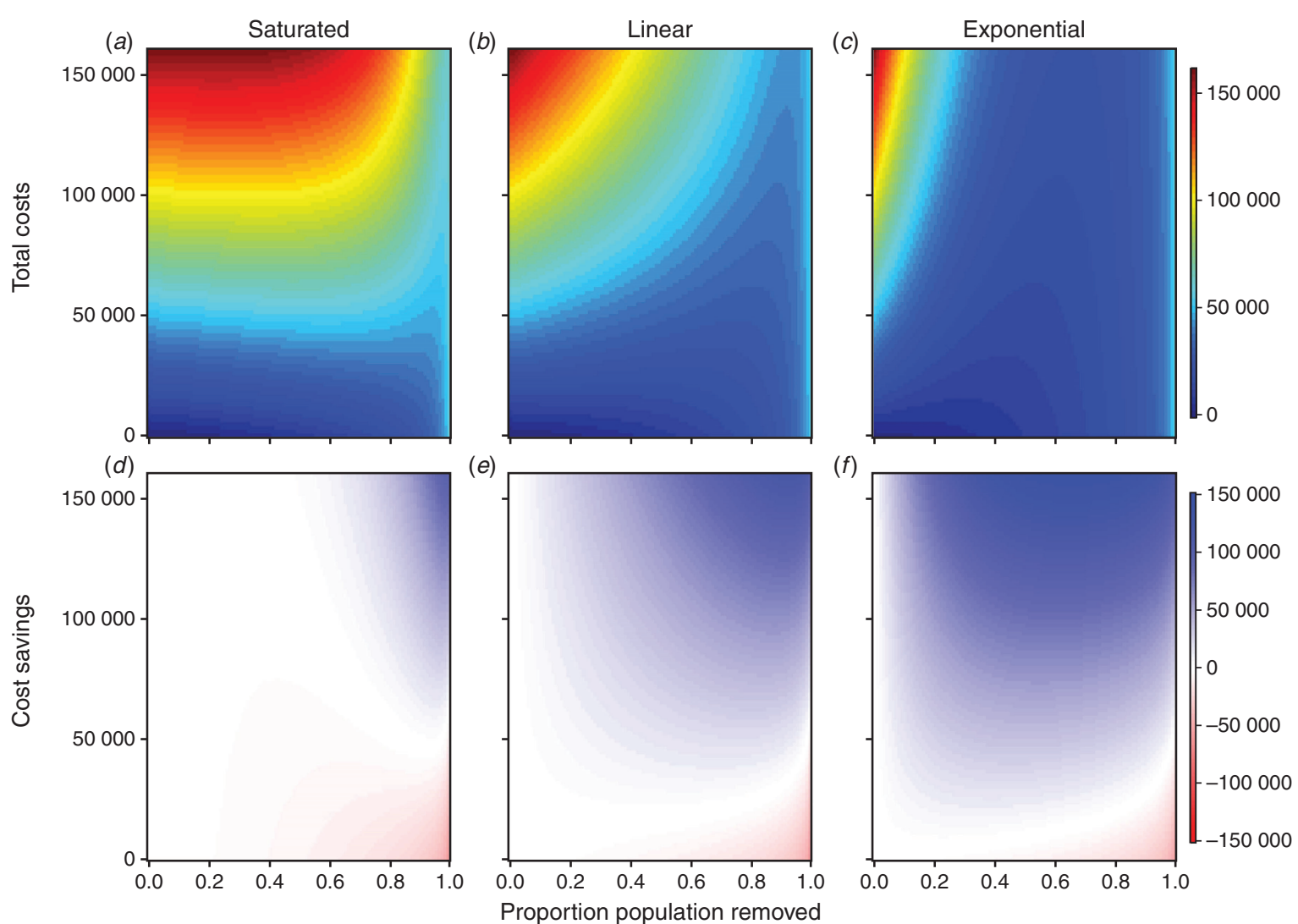

Fig. 6. Estimated total costs (damage costs plus management costs; top row) and cost savings over doing nothing (bottom row) for a range of initial damage costs ( $y$-axes) and proportions of the population removed ( $x$-axes) under three damage-density relationship scenarios: saturated $(A$ and $D)$, linear $(B$ and $E)$, and exponential $(C$ and $F)$. The total costs are shown ranging from low costs (blue) to high costs (red). The cost savings are shown in white when the costs are similar to the initial damage costs, blue for cost savings, and red for additional costs over the initial damage costs.

greater than $80 \%$. If a saturating relationship is representative of the damage-density relationship for wild pigs, our results suggest that it may be more cost-effective to conduct repeated removal events within a short time frame than to spread the same effort over a longer period or a larger area, especially at high-damage sites. In contrast, if the density-damage relationship is linear or exponential, substantial damage reduction can occur by reducing the population by $50 \%$, or only $20 \%$, respectively, both of which are substantially different levels of management effort. Thus, empirical work 
to determine the shape of this relationship is needed for managers to estimate the most cost-effective actions for a particular level of damage. Once this relationship is better understood, we can compare actual management costs to damage costs.

The damage-density relationship may not be constant across space and time, and management efforts are often conducted under the assumption that the damage reduction is greater at different times of year. For instance, the relationship between damage and density may be saturating or linear at some times of the year, but exponential at others. Managers may time removal events to occur immediately before planting or harvesting of specific crops, such as peanuts, because these crops are only targeted by pigs at those times of the year. In these cases, doing only two removal events - one right before planting and one right before harvest - may be the most cost-effective damage reduction strategy compared with conducting several flights in the middle of the growing season. Additionally, the removal rate is known to vary at different times of the year due to weather and seasonal deciduous canopy cover. Therefore, in addition to the fluctuating potential to reduce damage, the cost-effectiveness may change throughout the year due to changes in the costs of removing individuals. These are standard considerations that managers account for when planning removal work and are necessary to account for in models for management effectiveness.

We have provided a simplified version of how a damage-density relationship may look, and shown how important that relationship can be in connecting management to the objective of damage reduction. Single removal events can be beneficial for many reasons, even if the cost calculations do not suggest the reduction in damage is greater than the cost of removals. Aerial efforts may be employed to access sites that are not feasible to access from ground efforts (e.g. trapping or ground shooting) or to target areas that are particularly vulnerable to damage (e.g. predation of livestock, growth stage of crops). Additionally, the damage-density relationship may be more complex because different age classes or the different sexes might have a different impact on the damage incurred. While young pigs may be more influential on population growth, a single adult boar can cause a substantial amount of damage to the landscape. Thus, it may be most effective to use a removal strategy that targets the subset of the population that has the largest effect on the underlying objective (e.g. long-term population reduction or immediate damage reduction).

Reducing wild pig populations has the potential benefit of reducing damage costs; however, the reduction events are not without costs themselves. As a larger portion of the population is targeted for reduction, the costs of reduction increase exponentially (our results and Choquenot et al. 1999). The costs to implement reductions in populations can be compared with the potential cost savings of damage reductions, which may help justify expenses for removal work. Examining these cost trade-offs up front can be considerably beneficial for budget planning. In particular, population projections can help justify the need for large, up-front contributions to management efforts because these large initial investments may result in considerably lower long-term costs. In contrast, consistent smaller investments in removal work over time may have the same management costs as one initial, intensive reduction effort, but the long-term damage costs may be considerably higher as these may be simply 'mowing the grass' and not pushing a population towards elimination.

The damage-density relationship heavily influences how much population reduction is necessary to induce a cost savings. Generally, if the relationship is linear or exponential, doing almost any removal results in a cost savings unless there are little or no damage costs. Additionally, it is important to consider that reducing future damage costs by reducing the spread of the species to new areas, and preventing damage from occurring, may result in future savings. Site 1 is an example where the primary objective was to prevent the spread of wild pigs on the border of their range in Texas, to prevent future damage in neighbouring areas. Thus, even if current damage costs are low, anticipated future damage costs may warrant an immediate expenditure. Our results on the relationship between damage costs and population density could be used either for planning management against current damage levels or anticipated damage levels. However, the cost savings we show are short-term savings, not accounting for potential effects of management on suppressing geographic spread, which could lead to additional cost savings that we have not incorporated, presenting a challenge for future work. There is considerable value in examining these potential future costs that may result if wild pigs are allowed to spread to new areas. An actual accounting of the theoretical damage to a new area may make a strong case to focus removal efforts in areas with little current damage but that are on the edge of an invasion front instead of in areas with high current damage since the long-term damage may be considerably higher if the invasion is allowed to continue.

Repeated reduction events allowed us to estimate the abundance of wild pigs in each of our study areas while simultaneously reducing their numbers. In our study areas, we reduced the populations by an average of $31 \%$ after one flight and an average of $67 \%$ by the completion of three flights. If we had not conducted multiple removals, and thus were not able to estimate abundance, we would only have known that we had removed 157, 71 and 161 individuals in the respective sites (after one flight). In this case, we may have expected that we had impacted Sites 1 and 3 similarly because they had a similar number of animals removed, when in fact we had removed almost $40 \%$ of the population in Site 1 and only $30 \%$ of the population in Site 3. If we were to assume that both populations were at carrying capacity before management, this $10 \%$ difference in remaining population could mean 96 more days before the population in Site 3 returned to carrying capacity (i.e. potentially more time with fewer pigs causing damage on the landscape). This can be an important distinction when the objective is to reduce damage, which requires deciding how much control is cost-effective.

We also demonstrated how repeated flights can have a substantial impact on the population. Naïve removal rates based on the number of animals seen but not killed (due to pigs taking shelter in dense cover or no-fly zones), were very high ( $88 \%$ in this study and $94 \%$ in Davis et al. 2017). Our removal model demonstrates that the removal rate per flight was $\sim 27 \%$ (based on an eight-hour flight and our estimated hourly removal rate of $4 \%$ ) since many pigs go undetected. Our results show that 
additional flights lead to observing and thus removing more pigs and can produce costs savings (Fig. 6), suggesting that multiple flights over the same space can be cost-effective especially when damage reduction is the objective. Since we demonstrated how removal rates can vary by personnel and habitat (Fig. 3), the cost-effectiveness will vary under different personnel and habitat types. However, it is always important to recognise that as resources are limited, flying multiple times in one area will prevent having more flights over a wider area. Therefore, we may see considerable damage reduction in one site, but this could result in no damage reduction in other sites. The short-term damage costs may be equivalent at a broader spatial scale when conducting intensive removals in one area or less intensive removals on a broader area. The long-term benefits may vary, and examinations of these trade-offs is another important factor to consider for efficient management planning.

Another advantage to knowing the proportion of the population reduced by management is that the longer-term (in our case up to 5 years) effects of population reduction can be estimated when changes in abundance are known. Our results show that longer-term impact to a population was more affected by the proportion of the population removed compared with the growth rate except when the growth rate was high $(>1.8)$, indicating the importance of removing a larger percentage of the population to optimise management efficacy on a property or in an area.

Wildlife management is always conducted under constrained resources while attempting to address multiple management objectives (e.g. conserving native and game species, reducing invasive or overabundant species, protecting natural or agricultural resources), while satisfying the diverse interests of stakeholders (e.g. land owners, government agencies and a plethora of publics). Therefore, managing an overabundant population like wild pigs needs not only to be considered in terms of the most cost-effective strategy but also in what decisions maintain or improve stakeholder opinions and support. In some cases, it may not be cost-effective nor logistically possible to visit a property multiple times; however, the benefit in terms of fostering good relationships may be invaluable. The management strategies that ultimately are most beneficial for the landscape as a whole will be a balance of strategies that foster good relationships with stakeholders and ones that reduce the populations most effectively.

\section{Management implications}

We showed how cost-effectiveness of wild pig damage management by aerial gunning can be evaluated using removal data and population models. Despite the common belief that it is not cost-effective to conduct repeated flights over the same space within a short time frame, our results showed that repeat flights can increase cost-effectiveness especially when damage levels are high or the damage relationship is saturating. However, if damage levels are low or if the damage-density relationship is exponential, conducting one flight might be the most cost-effective approach. Our study was focussed on three sites in Texas where aerial gunning for wild pigs is a common management technique. In other states or in locations with generally lower densities there would be a much different cost-benefit calculation. However, the rational for monitoring during management and considering costs of damage and removal still hold. In cases where resources for conducting damage management are limited and locations are prioritised by landowner demand, our approach to estimating program-wide cost-effectiveness could be applied to data from a subset of areas to make inference in the broader system. Therefore, targeted checks on population efficiency and cost-effectiveness may be a practical approach while gaining important information.

\section{Conflicts of interest}

The authors declare no conflicts of interest.

\section{Acknowledgements}

Thanks to the Wildlife Services personnel (Thomas Taylor, Lance Nixon and Cole Taylor) who conducted aerial work for this project. We would like to thank two anonymous reviewers for helpful comments on this manuscript. Any use of trade, firm or product names is for descriptive purposes only and does not imply endorsement by the US government.

This research did not receive any specific funding.

\section{References}

Barrios-Garcia, M. N., and Ballari, S. A. (2012). Impact of wild boar (Sus $s c r o f a$ ) in its introduced and native range: a review. Biological Invasions 14, 2283-2300. doi:10.1007/s10530-012-0229-6

Baxter, P. W. J., Sabo, J. L., Wilcox, C., McCarthy, M. A., and Possingham, H. P. (2008). Cost-effective suppression and eradication of invasive predators. Conservation Biology 22, 89-98. doi:10.1111/j.1523-1739. 2007.00850.x

Bengsen, A. J., Leung, L. K. P., Lapidge, S. J., and Gordon, I. J. (2011). Using a general index approach to analyze camera-trap abundance indices. The Journal of Wildlife Management 75, 1222-1227. doi:10.1002/jwmg.132

Bengsen, A. J., Gentle, M. N., Mitchell, J. L., Pearson, H. E., and Saunders, G. R. (2014). Impacts and management of wild pigs Sus scrofa in Australia. Mammal Review 44, 135-147. doi:10.1111/mam.12011

Bevins, S. N., Pedersen, K., Lutman, M. W., Gidlewski, T., and Deliberto, T. J. (2014). Consequences associated with the recent range expansion of nonnative feral swine. Bioscience 64, 291-299. doi:10.1093/biosci/ biu015

Bieber, C., and Ruf, T. (2005). Population dynamics in wild boar Sus scrofa: ecology, elasticity of growth rate and implications for the management of pulsed resource consumers. Journal of Applied Ecology 42, 1203-1213. doi:10.1111/j.1365-2664.2005.01094.x

Bleier, N., Lehoczki, R., Újváry, D., Szemethy, L., and Csányi, S. (2012). Relationships between wild ungulates density and crop damage in Hungary. Acta Theriologica 57, 351-359. doi:10.1007/s13364-0120082-0

Buckland, S. T., Anderson, D. R., Burnham, K. P., Laake, J. L., Borchers, D. L. and Thomas, L. (2001) 'Introduction to Distance Sampling: estimating abundance of biological populations.' (Oxford University Press: Oxford, UK.)

Caley, P. (1993). Population dynamics of feral pigs (Sus scrofa) in a tropical riverine habitat complex. Wildlife Research 20, 625-636. doi:10.1071/ WR9930625

Caley, P. (1994). Factors affecting the success rate of traps for catching feral pigs in a tropical habitat. Wildlife Research 21, 287-292. doi:10.1071/ WR9940287

Campbell, T. A., and Long, D. B. (2009). Feral swine damage and damage management in forested ecosystems. Forest Ecology and Management 257, 2319-2326. doi:10.1016/j.foreco.2009.03.036 
Campbell, T. A., Long, D. B., and Leland, B. R. (2010). Feral swine behavior relative to aerial gunning in southern Texas. The Journal of Wildlife Management 74, 337-341. doi:10.2193/2009-131

Chee, Y. E., and Wintle, B. A. (2010). Linking modelling, monitoring and management: an integrated approach to controlling overabundant wildlife. Journal of Applied Ecology 47, 1169-1178. doi:10.1111/ j.1365-2664.2010.01877.x

Choquenot, D., Kilgour, R. J., and Lukins, B. S. (1993). An evaluation of feral pig trapping. Wildlife Research 20, 15-21. doi:10.1071/ WR9930015

Choquenot, D., Hone, J., and Saunders, G. (1999). Using aspects of predator-prey theory to evaluate helicopter shooting for feral pig control. Wildlife Research 26, 251-261. doi:10.1071/WR98006

Conover, M. R. (2001). 'Resolving Human-wildlife Conflicts: the Science of Wildlife Damage Management.' (CRC Press: Boca Raton, FL.)

Cowled, B. D., Elsworth, P., and Lapidge, S. J. (2008). Additional toxins for feral pig (Sus scrofa) control: identifying and testing Achilles' heels. Wildlife Research 35, 651-662. doi:10.1071/WR07072

Davis, A. J., Hooten, M. B., Miller, R. S., Farnsworth, M. L., Lewis, J., Moxcey, M., and Pepin, K. M. (2016). Inferring invasive species abundance using removal data from management actions. Ecological Applications 26, 2339-2346. doi:10.1002/eap.1383

Davis, A. J., Leland, B., Bodenchuk, M., VerCauteren, K. C., and Pepin, K. M. (2017). Estimating population density for disease risk assessment: the importance of understanding the area of influence of traps using wild pigs as an example. Preventive Veterinary Medicine 141, 33-37. doi:10.1016/j.prevetmed.2017.04.004

DeMaso, S. J., Guthery, F. S., Spears, G. S., and Rice, S. M. (1992). Morning covey calls as an index of northern bobwhite density. Wildlife Society Bulletin 20, 94-101.

Diefenbach, D. R., Palmer, W. L., and Shope, W. K. (1997). Attitudes of Pennsylvania sportsmen towards managing white-tailed deer to protect the ecological integrity of forests. Wildlife Society Bulletin 25, 244-251.

Fackler, P. L., and Haight, R. G. (2014). Monitoring as a partially observable decision problem. Resource and Energy Economics 37, 226-241. doi:10.1016/j.reseneeco.2013.12.005

Fagerstone, K. A., and Clay, W. H. (1997). Overview of USDA animal damage control efforts to manage overabundant deer. Wildlife Society Bulletin 25, 413-417.

Farnsworth, G. L., Pollock, K. H., Nichols, J. D., Simons, T. R., Hines, J. E., Sauer, J. R., and Brawn, J. (2002). A removal model for estimating detection probabilities from point-count surveys. The Auk 119, 414-425. doi:10.1642/0004-8038(2002)119[0414:ARMFED]2.0.CO;2

Gill, R. M. A. (1992). A review of damage by mammals in north temperate forests: 1. Deer. Forestry. International Journal of Forestry Research $\mathbf{6 5}$, $145-169$.

Gove, N. E., Skalski, J. R., Zager, P., and Townsend, R. L. (2002). Statistical models for population reconstruction using age-at-harvest data. The Journal of Wildlife Management 66, 310-320. doi:10.2307/3803163

Hauser, C. E., Pople, A. R., and Possingham, H. P. (2006). Should managed populations be monitored every year? Ecological Applications 16, 807-819. doi:10.1890/1051-0761(2006)016[0807:SMPBME]2.0.CO;2

Homer, C. G., Dewitz, J. A., Yang, L., Jin, S., Danielson, P., Xian, G., Coulston, J., Herold, N. D., Wickham, J. D., and Megown, K. (2015). Completion of the 2011 National Land Cover Database for the conterminous United States-Representing a decade of land cover change information. Photogrammetric Engineering \& Remote Sensing 81, 345-354.

Hone, J. (1995). Spatial and temporal aspects of vertebrate pest damage with emphasis on feral pigs. Journal of Applied Ecology 32, 311-319. doi: $10.2307 / 2405098$

Hone, J. (1996). Analysis of vertebrate pest research. In 'Proceedings of the Seventeenth Vertebrate Pest Conference.' (Eds R.M. Timm \& A.C. Crabb.) pp. 13-17. (University of California: Davis, CA.)
Hone, J. (2002). Feral pigs in Namadgi National Park, Australia: dynamics, impacts and management. Biological Conservation 105, 231-242. doi:10.1016/S0006-3207(01)00185-9

Linnell, J. D., Broseth, H., Odden, J., and Nilsen, E. B. (2010). Sustainably harvesting a large carnivore? Development of Eurasian lynx populations in Norway during 160 years of shifting policy. Environmental Management 45, 1142-1154. doi:10.1007/s00267-0109455-9

Lyons, J. E., Runge, M. C., Laskowski, H. P., and Kendall, W. L. (2008). Monitoring in the context of structured decision-making and adaptive management. The Journal of Wildlife Management 72, 1683-1692. doi: $10.2193 / 2008-141$

Massei, G., Cowan, D., Coats, J., Gladwell, F., Lane, J., and Miller, L. (2008). Effect of the GnRH vaccine GonaCon on the fertility, physiology and behaviour of wild boar. Wildlife Research 35, 540-547. doi:10.1071/ WR07132

Mellish, J. M., Sumrall, A., Campbell, T. A., Collier, B. A., Neill, W. H., Higginbotham, B., and Lopez, R. R. (2014). Simulating potential population growth of wild pig, Sus scrofa, in Texas. Southeastern Naturalist (Steuben, ME) 13, 367-376. doi:10.1656/058.013.0217

Moretti, M. (1995). Biometric data and growth rates of a mountain population of wild boar (Sus scrofa L.), Ticino, Switzerland. IBEX - Journal of Mountain Ecology 3, 56-59.

Naughton-Treves, L. (1998). Predicting patterns of crop damage by wildlife around Kibale National Park, Uganda. Conservation Biology 12, 156-168. doi:10.1046/j.1523-1739.1998.96346.x

Otto, S. P., and Day, T. (2007). 'A Biologist's Guide to Mathematical Modeling in Ecology and Evolution'. Vol. 13. (Princeton University Press, Princeton, IL.)

Parkes, J. P., Ramsey, D. S. L., Macdonald, N., Walker, K., McKnight, S., Cohen, B. S., and Morrison, S. A. (2010). Rapid eradication of feral pigs (Sus scrofa) from Santa Cruz Island, California. Biological Conservation 143, 634-641. doi:10.1016/j.biocon.2009.11.028

Pimentel, D. (2007). Environmental and economic costs of vertebrate species invasions into the United States. In 'Managing Vertebrate Invasive Species: Proceedings of an International Symposium'. (Eds G. W. Witmer, W. C. Pitt, K. A. Fagerston). pp. 13-17. (US Department of Agriculture, Animal and Plant Health Inspection Service, Wildlife Services, National Wildlife Research Center: Fort Collins, CO.)

Royle, J. A., and Dorazio, R. M. (2006). Hierarchical models of animal abundance and occurrence. Journal of Agricultural Biological \& Environmental Statistics 11, 249-263. doi:10.1198/108571106X129153

Rupp, S. P., Ballard, W. B., and Wallace, M. C. (2000). A nationwide evaluation of deer hunter harvest survey techniques. Wildlife Society Bulletin 28, 570-578.

Seward, N. W., Ver Cauteren, K. C., Witmer, G. W., and Engeman, R. M. (2004). Feral swine impacts on agriculture and the environment. Sheep \& Goat Research Journal 12, 34-40.

Shrnhur, A. J., Levy, O., and Dvir, D. (1997). Mapping the dimensions of project success. Project Management Journal 28, 5-13.

Sibly, R. M., and Hone, J. (2002). Population growth rate and its determinants: an overview. Philosophical Transactions of the Royal Society of London. Series B, Biological Sciences 357, 1153-1170. doi: $10.1098 /$ rstb.2002.1117

Slade, N. A., and Blair, S. M. (2000). An empirical test of using counts of individuals captured as indices of population size. Journal of Mammalogy 81, 1035-1045. doi:10.1644/1545-1542(2000)081<1035: AETOUC $>2.0 . \mathrm{CO} ; 2$

Snow, N. P., Jarzyna, M. A., and VerCauteren, K. C. (2017). Interpreting and predicting the spread of invasive wild pigs. Journal of Applied Ecology 54, 2022-2032. doi:10.1111/1365-2664.12866

St. Clair, K., Dunton, E., and Giudice, J. (2012). A comparison of models using removal effort to estimate animal abundance. Journal of Applied Statistics 40, 527-545. doi:10.1080/02664763.2012.748016 
Timmons, J. B., Mellish, J., Higginbotham, B., Griffin, J., Lopez, R. R., Sumrall, A., Cathey, J. C., and Skow, K. (2012). Feral Hog Population Growth, Density, and Harvest in Texas. Texas A\&M AgriLife Extension Service Report. (Texas A\&M University: College Station, TX.)

VerCauteren, K. C., Anderson, C. W., van Deelen, T. R., Drake, D., Walter, W. D., Vantassel, S. M., and Hygnstrom, S. E. (2011). Regulated commercial harvest to manage overabundant white-tailed deer: an idea to consider? Wildlife Society Bulletin 35, 185-194. doi:10.1002/ wsb. 36

Waithman, J. D., Sweitzer, R. A., Vuren, D. V., Drew, J. D., Brinkhaus, A. J., Gardner, I. A., and Boyce, W. M. (1999). Range expansion, population sizes, and management of wild pigs in California. The Journal of Wildlife Management 63, 298-308. doi: $10.2307 / 3802513$

West, B. C., and Parkhurst, J. A. (2002). Interactions between Deer Damage, Deer Density, and Stakeholder Attitudes in Virginia. Wildlife Society Bulletin 30, 139-147.

Williams, B. L., Holtfreter, R. W., Ditchkoff, S. S., and Grand, J. B. (2011). Trap style influences wild pig behavior and trapping success. The Journal of Wildlife Management 75, 432-436. doi:10.1002/jwmg.64

Zippin, C. (1958). The removal method of population estimation. The Journal of Wildlife Management 22, 82-90. doi:10.2307/3797301 